\title{
LEI SARBANES-OXLEY: RELEVÂNCIA DO USO DE UM SISTEMA DO TIPO ERP PARA AUTOMAÇÃO DOS REGISTROS CONTÁBEIS E FINANCEIROS
}

Lilian Meira Purcinelli

Mestranda em Controladoria e Finanças Empresariais da Universidade Presbiteriana Mackenzie (UPM). Cumpre estágio para dupla titulação do mestrado no Instituto Politécnico da Guarda, em Portugal. 


\section{RESUMO}

O desenvolvimento da informática e das tecnologias de informação contribuiu para que os processos de geração, difusão e armazenamento do conhecimento nas organizações estejam sempre em processo de mudança e no sentido de melhor atender às demandas das organizações. Os desafios relacionados com a integração dos processos e dos sistemas de tecnologia e gestão estão em identificar possíveis não conformidades, erros, duplicidades ou falhas que possam orientar os gestores a promover oportunidades de melhoria e garantir a conformidade com as políticas e os procedimentos estabelecidos pela empresa. A contribuição deste estudo está em analisar e discutir a relevância do uso de um sistema do tipo ERP para automação dos registros contábeis e financeiros, especialmente na integração dos processos e no estabelecimento de controles internos eficientes para a área de sourcing das despesas operacionais - SG\&A (Opex) - e de investimentos (Capex), por meio de um processo de compras integrado end-to-end, para atender às determinações da Lei Sarbanes-Oxley (SARBANES; OXLEY, 2002).

\section{PALAVRAS-CHAVE}

Despesas operacionais. Lei Sarbanes-Oxley. Registros financeiros integrados. ERP.

\section{INTRODUÇÃO}

O desenvolvimento da informática e das tecnologias de informação contribuiu para que os processos de geração, difusão e armazenamento do conhecimento nas organizações estejam sempre em processo de mudança e no sentido de melhor atender às demandas das organizações (CAMPOS FILHO, 1994). Segundo Campos Filho (1994), a combinação de literatura, tecnologia de informação e gestão do conhecimento está relacionada com o uso de sistemas tecnológicos para o compartilhamento de informações ou conhecimento.

Ainda segundo Campos Filho (1994), os sistemas de informação (SI) são, por sua vez, um fator imprescindível na atividade de qualquer entidade, organização ou instituição. Assim, os SI podem ser entendidos, do ponto de vista gerencial, como uma combinação estruturada de informação, recursos humanos, tecnologias de informação e práticas de trabalho, organizados de maneira a viabilizar o atingimento dos objetivos e das metas da organização.

O objetivo deste estudo é discutir a relevância do uso de um sistema do tipo Enterprise Resource Planning (ERP) para a automação dos registros contábeis e fi- 
nanceiros, de acordo com as determinações da Lei Sarbanes-Oxley - SOX (SARBANES; OXLEY, 2002).

Este trabalho se concentrou nos registros contábeis e financeiros, especialmente na integração dos processos e no estabelecimento de controles internos na área de compras, tendo em vista os requisitos da Lei SOX, da seção 404, relacionados às despesas operacionais (operacional expenditure - Opex) e de investimentos (capital expenditure - Capex).

O ERP “é um sistema integrado de aplicações e módulos" (CALDEIRA, 2008, p. 27) que permite a integração entre as diversas áreas de uma empresa, como estoques, unidades de venda, recursos humanos, marketing, finanças etc. Caldeira (2008) destaca ainda que os benefícios esperados de um sistema ERP estão relacionados à melhoria de produtividade e de redução de custos, e à maior eficiência no desempenho operacional dos processos de negócio.

Este estudo discute uma série de ações práticas que a empresa e seus gestores podem tomar com relação à supervisão global e à manutenção de um processo end-to-end, conhecido como um processo desenhado de ponta a ponta.
No contexto de garantir a governança de um processo end-to-end, entende-se como relevante o papel da tecnologia, nesse caso, um sistema ERP, porque este pode desempenhar não só em termos de eficiência, monitoramento e medição de desempenho, mas também na identificação de riscos operacionais e detecção de erros ou desvios de processo (R\&D SOLUTIONS, 2016).

Em relação às despesas operacionais, destaca-se a obrigatoriedade da classificação correta das receitas e despesas da empresa, de acordo com a sua função ou natureza (CPC, 2011).

Porém, destaca-se que ainda há diferenças no reconhecimento e na divulgação desses gastos entre as empresas nos diversos países, onde ainda não há uma padronização dos registros efetuados na conta de despesas de vendas, gerais e administrativas - despesas operacionais, conta em inglês denomida por Selling, General \& Administrative Expense SG\&A (ELIAS; BORGERT, LUNKES, 2018).

De acordo com a Estrutura Conceitual Básica (CPC, 2011), as características qualitativas da informação contábil - comparabilidade, verificabilidade, tempestividade e compreensibilidade - devem ser fornecidas pelas demonstrações contábeis, 
assim como as informações fornecidas por outros meios.

Nesse contexto, essas informações úteis podem ser obtidas do sistema ERP, gerencial ou contábil, que servirão como base, suporte e apoio para a aplicação dos requisitos da seção 404 da Lei SOX (SARBANES; OXLEY, 2002).

Os desafios relacionados com a integração dos processos e dos sistemas de tecnologia e gestão estão em identificar possíveis não conformidades, erros, duplicidades ou falhas que possam orientar os gestores a promover oportunidades de melhoria e garantir a conformidade com as políticas e os procedimentos estabelecidos pela empresa.

A relevância deste estudo está em analisar e discutir o uso de um sistema do tipo ERP para automação dos registros contábeis e financeiros, especialmente na integração dos processos e no estabelecimento de controles internos eficientes para a área de sourcing das despesas operacionais - SG\&A (Opex) - e de investimentos (Capex), por meio de um processo de compras integrado end-to-end.

No contexto analisado neste estudo, o estabelecimento de controles internos eficientes tem o objetivo principal de identificar pontos de fragilidade e/ou possíveis erros que possam comprometer a conformidade com as políticas e os procedimentos da empresa, e que atendam aos requisitos estabelecidos na seção 404 da Lei SOX, e, consequentemente, melhorar os resultados de performance econômico-financeira das empresas.

Este estudo se justifica porque analisa os controles internos eficientes para a área de sourcing das despesas operacionais SG\&A (Opex) - e de investimento (Capex), e os processos que possam melhorar os resultados de performance econômico-financeira das empresas.

Entretanto, nota-se um gap na literatura ou mesmo uma carência nos estudos acadêmicos que não têm sido direcionados para entender o impacto da falta de controle desses gastos nas empresas, que também fazem parte da cadeia de suprimentos, mesmo que em menor dimensão, mas não menos importante, e que são significativas no total dos gastos e podem consumir a lucratividade da empresa ou mesmo gerar resultados negativos.

Os gastos desembolsáveis com as despesas operacionais - SG\&A (Opex) - e de investimentos (Capex) têm se mostrado relevantes para o desempenho das organizações. Contudo, a despeito dessa impor- 
tância, no campo prático nota-se que os controles internos implantados na área de sourcing têm se voltado mais para itens como matéria-prima ou materiais destinados ao processo produtivo de indústrias, classificados como estoque, como análise da curva $\mathrm{ABC}$, conforme descrito por Dias (2012), concretizando o gap analisys na implantação de controles específicos para essa área.

As implicações práticas sobre a questão do estudo estão associadas com mecanismos de controle e de segurança confiáveis, especificamente para a área de compras relacionadas às despesas operacionais - SG\&A (Opex) - ou de investimentos (Capex), referentes às aquisições de bens e às prestações de serviços das empresas fornecedoras, com o objetivo de

- promover a melhoria contínua dos processos que possam garantir a conformidade com as políticas e os procedimentos estabelecidos pela empresa;

- fazer o rastreamento do processo de compras end-to-end, com o suporte de um sistema do tipo ERP integrado;

- promover a segregação de funções entre as áreas;

- obter a transparência e confiabilidade nesse processo e na identificação de possíveis não conformidades, erros, duplicidades ou falhas;

- reduzir as despesas operacionais SG\&A (Opex) - e melhorar a eficiência na aplicação dos investimentos (Capex) para viabilizar o atingimento de metas estabelecidas pela empresa.

No processo de produção descrito por Plossl (1993), a área de sourcing é um dos setores que contribuem com informações para empresa, por meio de sua parceria com os fornecedores e da comunicação com toda a organização, que tem como tarefa primordial o desenvolvimento e a parceria com fornecedores, e coordenação do fluxo de informações entre fornecedor e a empresa compradora (cliente), juntamente com a área que necessita de um material ou serviço específico.

Buscou-se por meio deste estudo analisar e discutir como utilizar as técnicas adequadas no planejamento de necessidades de comprar materiais e serviços, alinhadas com o plano estratégico da empresa, o desenvolvimento de fornecedores e a utilização de processo virtual para fazer a gestão dos custos relevantes, dentro de um processo integrado, tanto interno como externo, para minimizar custos operacionais e buscar o atingimento de metas, 
como redução dos gastos e melhoria dos resultados operacionais das empresas.

Este estudo busca também contribuir para a melhoria dos processos de compras relacionadas às despesas operacionais SG\&A (Opex) - ou de investimentos (Capex), para obter ganho de produtividade da área, eliminar processos manuais, retrabalhos, trânsito de papéis e documentos, fornecer transparência no processo, detectar e evitar duplicidade de registros contábeis ou em contas indevidas, e gerar informação útil e relevante representada com fidedignidade (CPC, 2011; HENDRIKSEN, 2018).

Com o aprofundamento dos estudos, buscou-se explorar e analisar procedimentos como:

- Realização de processo licitatório (Bid) de forma transparente e sistemática sem influência do comprador.

- Aprovação sistemática da melhor proposta recebida e que contribua com a economia financeira para empresa e a qualidade dos materiais, bens e serviços adquiridos.

- Vinculação da proposta aprovada ao contrato jurídico ou acordo comercial.

- Promoção do controle sistemático da aquisição dos materiais e bens e reali- zação dos serviços, da requisição até o pagamento.

- Gestão de riscos de fornecimento, realização dos contratos, monitoramento de pedidos e prazos de pagamentos.

- Segregação de função entre as áreas envolvidas.

- Conferência e acolhimento dos documentos fiscais de forma eletrônica.

- Registros contábeis, fiscais e de pagamento de cada operação de forma sistemática e automática, sem exceções ao processo.

Diante disso, adicionalmente, pretende-se analisar e discutir os aspectos relevantes para se ter um processo de compras seguro, eficiente e transparente, com o uso de tecnologias e serviços capazes de propor soluções inovadoras e criativas para resolver problemas de caráter econômico-financeiro na área sourcing, maximizando os recursos da empresa e apoiando a segurança dos controles internos, de modo a promover a gestão da segurança da informação, dos colaboradores, dos fornecedores e do patrimônio da entidade, com ações de intervenção em nível de controles internos, buscando a segurança dos registros contábeis, fiscais e financeiros. 


\section{CONTEXTO E A REALIDADE INVESTIGADA}

De acordo com os indicadores de rentabilidade das empresas não financeiras de três grandes setores da economia - indústria, comércio e serviços - e com base em pesquisa divulgada pelo Instituto de Estudos para o Desenvolvimento Industrial - Iedi (2018), que analisou os dados contábeis obtidos dos balanços patrimoniais e das demonstrações financeiras das 322 empresas com registro na Comissão de Valores Mobiliários (CVM), verificou-se um retrocesso na lucratividade das empresas, muito em função de fatores como a inconsistência da recuperação econômica, a paralisação dos caminheiros, a elevada incerteza do cenário político etc., que levou à redução das expectativas do Produto Interno Bruto (PIB), no último ano, pela metade, de $3 \%$ para $1,4 \%$, segundo a pesquisa Focus.

Em linha com os dados apresentados nesta pesquisa do Iedi e de acordo com estudos feitos pela Deloitte (2018), a margem de lucro das empresas de varejo global é de 3,2\%, e o retorno composto sobre os ativos é de 3,3\%. Isso mostra que as empresas desse setor no Brasil tem um gap a ser superado para conseguir se equiparar às empresas globais.

\section{DIAGNÓSTICO DA SITUAÇÃO- -PROBLEMA E/OU OPORTUNIDADE}

Os dados apresentados na pesquisa do Instituto de Estudos para o Desenvolvimento Industrial (2018) corroboram o que afirma Dias (2012) de que existe uma demanda constante para redução de custos, principalmente dos materiais utilizados no processo operacional, já que podem representar uma parcela importante na estrutura de custo total da demonstração do resultado das empresas, a depender do setor analisado.

O estudo aqui proposto, de maneira geral e com base no conceito da aplicação, conclui que há uma limitação técnica para implantação desse processo, que é o uso de um sistema integrado ERP, para que possa controlar o processo de compras end-to-end. Em contraponto, entende-se que esse processo ou os conceitos aqui apresentados podem ser aplicados em qualquer tipo de empresa. 
ANÁLISE DA SITUAÇÃO-

-PROBLEMA E PROPOSTAS DE INOVAÇÃO/INTERVENÇÃO/ RECOMENDAÇÃO

A proposta de um modelo de fluxo end-to-end totalmente integrado no âmbito do sistema de controle interno, relacionada às aquisições de bens e materiais e à contratação de serviços, com ações e melhorias para otimização desse processo, visando obter a melhor eficácia, eficiência, economia e qualidade processual nessa área, pode trazer e incrementar vantagem competitiva para a empresa.

Na Figura 1, apresenta-se um fluxo de macroprocesso integrado end-to-end que se propõe neste estudo e que foi validado pelas entrevistas feitas com as pessoas envolvidas com esse tipo de sistema, do meio profissional, e que estudam temas relacionados, do meio acadêmico.

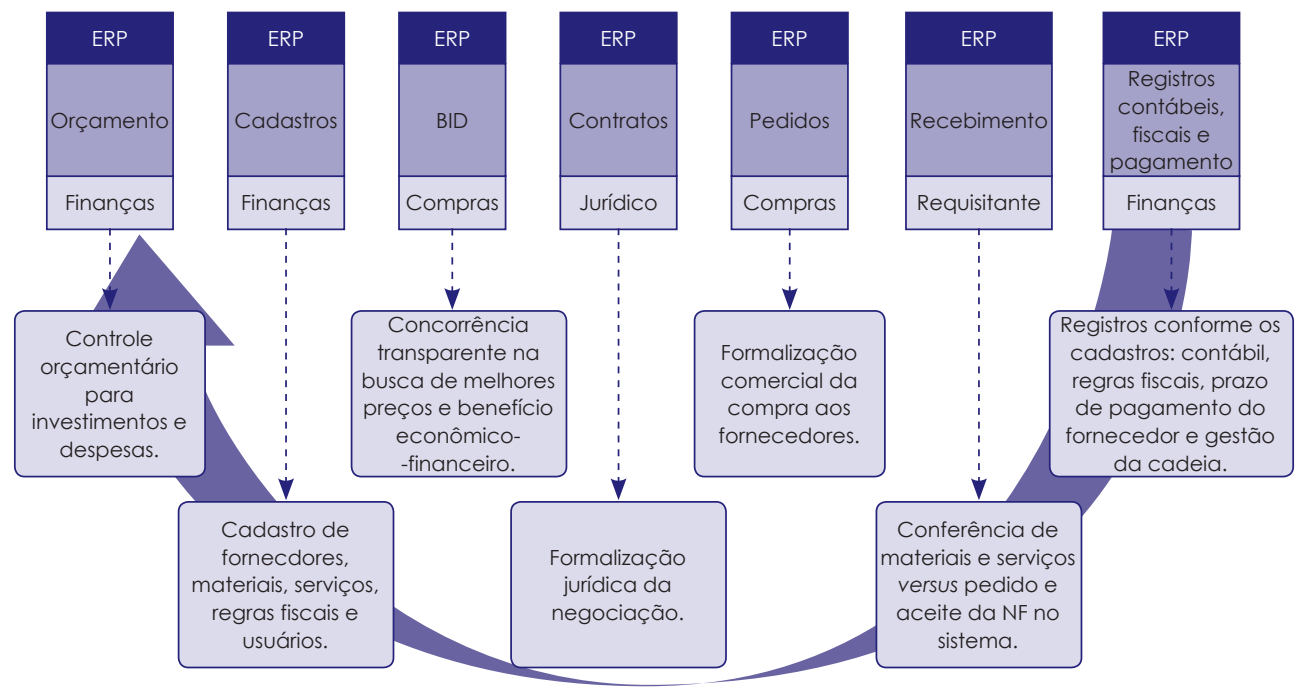

Workflow de aprovação de acordo com as alçadas, perfis e com Governança Corporativa em todas as etapas do processo.

Descrição clara dos procedimentos em todas as etapas do processo e formalização das regras em políticas.

Identificação dos riscos de controle e/ou melhoria de processos com base em KPIs para o desempenho de uma boa gestão.

FIGURA 1 - Macroprocesso integrado end-to-end

Fonte: Elaborada pela autora com base em livros de processos operacionais, auditoria e de informática. 
Assim, a empresa procura controle administrativo (processos e políticas) e sistêmico (cibernético), conforme sugerido por Malmi e Brown (2008), para fazer o rastreamento do processo de compras end-to-end, implantar a segregação de funções em todas as áreas de negócio, promover a transparência e a confiabilidade no processo de compras, implementar políticas e procedimentos nesse processo, e, por fim, buscar a melhoria contínua dos processos (SARBANES; OXLEY, 2002).

Dessa forma, para atingir o objetivo proposto neste estudo, de acordo com as seções estabelecidas pela Lei SOX, propõem-se as seguintes ações práticas (SARBANES; OXLEY, 2002):

- Mapear as atividades relacionadas ao processo licitatório (Bid).

- Padronizar os bens, materiais e serviços no sistema.

- Construir fluxogramas do processo de compras.

- Identificar os pontos de decisão e as suas vulnerabilidades.

- Definir e atribuir responsabilidades em cada etapa do processo.

- Relacionar as políticas e os procedimentos do processo de compras.
- Identificar as não conformidades ao longo do processo de compras e as suas implicações.

- Propor melhorias no processo de compras para, de modo sistematizado, mitigar os erros ou as inconformidades.

- Apresentar um sistema de controle interno eficaz, eficiente, econômico e com qualidade, como apoio à decisão econômico-financeiro no processo de compras de bens, materiais e prestação de serviços da empresa.

De acordo com o macroprocesso (Figura 1), apresentam-se a seguir os conceitos e/ou passos de cada uma das sete áreas envolvidas no fluxo proposto.

\section{Passo 1: Processo de orçamento}

O orçamento faz parte da contabilidade gerencial e é entendido como um subconjunto do sistema de controle organizacional (STEDE; MARKYOUNG; CHEN, 2005). O orçamento empresarial consiste em um dos artefatos utilizados pelos gestores para fazer a gestão e tomada de decisão (MALMI; BROWN, 2008).

Nesse contexto, é possível dizer que não existe uma norma predefinida de como o orçamento deve ser criado ou uti- 
lizado, uma vez que ele deve considerar as características individuas de cada entidade (FREZATTI et al., 2011).

A etapa orçamentária representa a ação da empresa de transpor para o sistema informatizado, aqui sugerido, um sistema ERP, o seu planejamento orçamentário para que seja feito o controle dos gastos das despesas operacionais (Opex) e de investimentos (Capex).

A gestão orçamentária deve ser de responsabilidade da área de finanças, que disponibilizará os recursos aos usuários de todos os departamentos da empresa, que os utilizarão, ao longo de um período ou exercício, por meio das requisições de gastos.

Esse processo de controle orçamentário permitirá que a empresa faça uma gestão eficiente da aplicação dos seus recursos em tempo real, uma vez que o sistema pode ser atualizado na periodicidade a ser definida (por hora/minutos ou dia). Além disso, a empresa terá acesso a relatórios para fazer a gestão do orçado versus realizado com maior acuracidade.

Com o uso contínuo do processo integrado, ao longo da rodada de mais alguns ciclos operacionais, a empresa, no médio prazo, obterá informações consoli- dadas e tempestivas, ou seja, quanto mais amadurecido for o processo, maior será o nível de confiança nas informações obtidas e, consequentemente, maior será a precisão na previsão dos gastos da empresa, atingindo aqui o estágio total da institucionalização e a etapa da sedimentação do uso dos processos (CLEGG; HARDY; NORD, 2012).

\section{Passo 2: Processo de cadastros}

O cadastro faz parte da etapa de controle de gestão com o uso de ferramentas que permitam aos gestores identificar problemas e garantir que ele esteja de acordo com os planos preestabelecidos pela empresa.

O cadastro apresentado neste estudo está subdividido em três subprocessos. O primeiro é o cadastro de itens, conforme demonstrado na etapa B da Figura 1, o qual consiste na criação de itens que podem ser agrupados em catálogos ou categorias, em que cada item ganha uma classificação contábil e é vinculado a uma conta de despesa (Opex) ou de investimento (Capex) e integrado ao cadastro das regras fiscais envolvidas nas transações operacionais. 
Em um primeiro momento, o cadastro dos itens de bem, material ou serviço deve sofrer um saneamento e, após a implantação, passar por uma manutenção periódica para manter atualizado o controle e a gestão das peculiaridades exigidas em algum processo específico da cadeia de compras.

Entretanto, para garantir um cadastro de forma padronizada, o item deve receber desde dados básicos até complementos técnicos, quando necessário. Ao final, cada item receberá um código numérico que o individualizará e que será sempre utilizado no processo de compras.

O segundo subprocesso de cadastro é o do fornecedor e requer que seja construído de maneira colaborativa, em que o fornecedor faz um pré-cadastro e fornece todos os dados obrigatórios definidos pela empresa.

O último subprocesso é o cadastro de usuários, em que deve ser feito um mapeamento das atividades em cada etapa do processo sem perder a visão do macroprocesso integrado, para definição dos perfis de acesso ao sistema, o que vai garantir a devida segregação das funções executadas por usuário.

Por causa das questões de segregação de funções e especificações técnicas contá- beis e fiscais envolvidas na criação e manutenção desse cadastro, é recomendado que ele seja de responsabilidade de uma área independente dos usuários que utilizam o sistema. Neste estudo, recomenda-se a área de finanças como a mais adequada.

\section{Passo 3: Processo licitatório (Bid)}

O uso crescente dos sistemas informáticos e da tecnologia da informação e comunicação tem se mostrado como um fator diferencial para a melhoria da integração e organização da cadeia de suprimentos, na busca por atingir a eficácia e eficiência de produtividade (KETIKIDIS et al., 2010).

Acompanhando o crescimento do uso do comércio eletrônico, o conceito do e-procurement recebeu uma adesão global, que não se limitou ao setor privado e também vem crescendo no setor público (DEVARAJ; MISHRA; VAIDYANATHAN, 2012).

O e-procurement é mais do que uma decisão de compra on-line. Sua função inclui a construção de relacionamento entre fornecedores e compradores, além de abranger a reestruturação de processos interorganizacionais dirigidos por transa- 
ções e concentrar-se na automatização de fluxos de trabalho, consolidando e alavancando o poder de compra das empresas (CALDEIRA, 2008).

A partir dessa análise, foi verificado que o processo de compras nasce com a identificação da necessidade da realização de um gasto, aqui denominado de requisição de compras (RC). Ele pode ser iniciado por uma ação nova do usuário ou disparado automaticamente por uma necessidade identificada pelo próprio sistema, baseado em regras de negócio predefinidas pelo usuário.

O benefício das RCs automáticas será tanto maior quanto maior for o nível de amadurecimento do processo. Por exemplo, após a rodada de um ciclo, o sistema dispara um aviso para criação de uma RC, $n$ dias antes do vencimento de um contrato ou acordo comercial. Somente após a aprovação da RC, o comprador receberá uma demanda para que se inicie o processo de compras.

O processo de Bid pode ser feito por meio de cotação, leilão, carta-convite, entre outros tipos, com, no mínimo, três fornecedores. Para que haja transparência e credibilidade, o ponto principal desse processo, que deve ser eletrônico, é a determi- nação de uma data de início e fim para recebimento e abertura das propostas e dos orçamentos, de forma sigilosa, ou seja, durante o período estipulado para recebimento das propostas, nenhum usuário deve ter acesso ao conteúdo e às informações enviados pelos fornecedores.

Somente após a finalização do prazo de retorno dos fornecedores, caberá ao comprador analisar as ofertas recebidas, demonstrando por meio de um mapa comparativo MC, a sugestão e justificativa da oferta que se mostrar mais vantajosa para a empresa, de acordo com as especificações estabelecidas na abertura do Bid e solicitadas pelo requisitante no início do processo na RC.

Esse MC deve ser enviado para aprovação dos gestores responsáveis pelo gasto, ou seja, a área requisitante. Em caso de reprovação por parte do gestor da área requisitante, o processo de compras é finalizado. Em caso de aprovação, o comprador responsável pela compra inicia a formalização da contratação do fornecedor escolhido.

\section{Passo 4: Processo de contratos}

O contrato, segundo o artigo 875 do Código Civil brasileiro, é o ato pelo qual se 
transmite a propriedade de uma coisa, ou outro direito, mediante um preço.

Os estudos desenvolvidos pelos acadêmicos e economistas Oliver Hart e Bengt Holmström, que, em 2016, receberam o Prêmio Nobel de Economia, analisaram o que se pode fazer para melhorar a eficiência dos contratos. Nesse sentido, os estudiosos procuraram mostrar a importância de um contrato que seja benéfico para todos os envolvidos.

A operacionalização dos custos de transação é otimizada quando outras formas de acordo entre as partes são utilizadas sob a perspectiva relacional para tornar eficiente a estrutura de governança do relacionamento.

A próxima fase do processo a ser desenvolvida é a formalização jurídica da negociação com o fornecedor, que pode ser feito por meio do contrato jurídico e, posteriormente, a criação do acordo comercial (AC), no sistema com base na proposta escolhida e aprovada pelo requisitante demonstrada no MC.

Esse processo pode trazer alguns benefícios para a empresa, como o controle do valor do gasto contratado e aprovado, sem permitir que seja realizado um gasto de valor superior ou sem a devida formalização da negociação comercial.

Além disso, após a rodada de um ciclo operacional, esse controle da validade do contrato por meio do AC permitirá que o sistema dispare um aviso para o requisitante $n$ dias antes da data de vencimento dele, e, adicionalmente, o sistema enviará um aviso para a criação de uma RC, de forma automática.

\section{Passo 5: Processo de pedidos}

A governança corporativa pode ser entendida como um conjunto de procedimentos sistemáticos que buscam reduzir custos relacionados a questões de agência. A governança possui uma relação com desempenho das organizações por meio das práticas adotadas nas empresas (SILVEIRA, 2004).

Nesse sentido, a criação e gestão dos pedidos gerados pela própria empresa propiciam a governança da relação comercial, em que, apesar de existir um compromisso comercial e contratual, caberá à empresa, como cliente (principal), definir as condições em que ela prefere receber o bem, o material ou a realização do serviço contratado com o fornecedor (agente). 
Dessa forma, após assinatura do contrato jurídico e aprovação do AC, os itens e valores ficam disponíveis no sistema para criação da solicitação de compras ao fornecedor, aqui denominado como pedido de compras (PC). Esse processo representa a formalização comercial e operacional da empresa com o fornecedor.

O PC deve ser submetido a um workflow de aprovação (controle sistêmico) pelo gestor responsável pela requisição de compras, de acordo com os valores e cargos (controle de alçadas de aprovação) definidos nas políticas e nos procedimentos (controles administrativos) da empresa (MALMI; BROWN, 2008).

Nesse processo, o sistema deve fazer o controle orçamentário do gasto e não permitir a geração de um PC sem que haja um AC aprovado e verba disponível no sistema (budget de Opex ou Capex). Após a rodada de um ou mais ciclos, quando o processo atingir uma fase de amadurecimento, a validação da existência de verba disponível poderá ser implantada na fase inicial do processo, que é a RC.

Somente após a última alçada de aprovação, o PC é enviado ao fornecedor, de forma automática, pelo sistema, por meio de um documento digital e com sequencial numérico (Exemplo: 145.345).

O fornecedor deve, então, acessar o seu PC no sistema, devidamente aprovado pela empresa contratante. A partir do recebimento do PC aprovado, o fornecedor está autorizado a faturar e enviar o bem ou material ou iniciar a realização do serviço contratado, fazendo constar o número do respectivo $\mathrm{PC}$ a $\mathrm{AC}$ na nota fiscal.

Cabe ainda ao fornecedor fazer o vínculo eletrônico do Documento Auxiliar da Nota Fiscal eletrônica - DANFe (arquivo XML para bens tributados pelo Imposto sobre Circulação de Mercadorias e Serviços - ICMS) ou da nota fiscal eletrônica de serviço (NFe para serviços tributados pelo Imposto sobre Serviços - ISS) ao PC. Somente após cumprir esse procedimento, sem erros ou pendências identificadas pelo sistema, o fornecedor poderá fazer a entrega do bem ou material na unidade destino.

Após a conclusão do espelhamento do documento fiscal ao PC, o sistema envia uma mensagem automática, por e-mail, ao comprador e ao requisitante, informando que o bem ou material foi faturado e está sendo enviado para entrega no local de destino ou que o serviço já foi realizado. 


\section{Passo 6: Processo dos recebimentos}

A logística pode ser entendida não apenas como um processo da gestão dos fluxos dos produtos e serviços entre fornecedores e clientes, mas também da gestão de materiais (materials management). Dessa forma, a logística deve integrar duas ou mais atividades com o fim específico de programar, concretizar e controlar um fluxo eficiente de materiais e produtos entre o local de origem e o local de consumo (MOURA, 2006).

A etapa do recebimento representa a última fase operacional nesse processo integrado. A recepção física do bem, do material ou da confirmação da realização do serviço deve ser realizada pela unidade de destino ou requisitante somente se o processo anterior foi realizado sem nenhuma pendência. Divergências ou erros devem ser tratados e solucionados antes do recebimento físico do bem, do material ou da confirmação da realização do serviço.

Após a conferência física do material, cabe ao recebedor acessar o sistema, mediante senha de acesso compatível com o perfil definido para essa atividade, devidamente mapeada na fase inicial do projeto no subprocesso de cadastro de usuários, e confirmar o recebimento da mercadoria ou da realização do serviço.

\section{Passo 7: Processo dos registros contábeis, fiscais e de pagamento}

A contabilidade é uma atividade cuja função é fornecer informação quantitativa e qualitativa, de natureza econômico-financeira, sobre as entidades para a tomada de decisões econômicas nas organizações (CPC , 2011).

Contudo, esse conceito e a maneira de entender a contabilidade têm evoluído ao longo do tempo, acompanhando, assim, as mudanças e transformações sociais e tecnológicas ocorridas em todas as áreas do conhecimento. A obtenção de informações úteis à tomada de decisões muitas vezes é um problema recorrente entre os gestores e demais agentes envolvidos (LOPES; MARTINS, 2007).

Após o recebimento do documento fiscal no sistema, os registros contábeis, fiscais e de contas a pagar ocorrem de forma automática de acordo com as padronizações definidas no cadastro do item e do fornecedor.

A última etapa do processo integrado ocorre de forma automática, que pode ser 
total ou parcial, com alguma revisão adicional que a empresa entenda que deva ser feita em algum processo sensível ou que represente algum risco maior.

Esse fluxo integrado permitirá a extração de relatórios com informações geradas pelo sistema, gerencial ou contábil, de forma tempestiva, cujas informações foram alimentadas em todas as etapas da cadeia, com a devida segregação, bem como a identificação das responsabilidades de cada usuário.

Assim, de modo a potenciar os benefícios de um processo integrado, cabe à empresa, adicionalmente, as seguintes ações:

- Garantir a transparência no processo de compras de bens ou a contratação de serviços.

- Realizar a gestão do processo de compra com as empresas contratadas, garantindo que todas as compras que não passam pelo processo licitatório (Bid) implicam uma classificação como um desvio de processo ou uma compra de emergência.

- Aprovar os documentos, de modo sistêmico, de acordo com as alçadas definidas em cada etapa do processo.

- Fazer a gestão do tempo médio de entrega de pedidos.
- Identificar os pedidos em aberto acima de $\mathrm{x}$ dias sem a entrega efetiva de material ou realização do serviço.

- Controlar as quebras de pedidos para driblar as alçadas de aprovação (quantidade de pedido, mesmo fornecedor, mesmo item, mesma unidade no período de $\mathrm{x}$ dias).

- Identificar os pedidos emitidos após entrega do material ou realização do serviço (data do pedido após a emissão da nota fiscal).

- Fazer a gestão do prazo médio de pagamento (data de entrega do material versus data do pagamento).

- Realizar de forma eficiente a gestão do fluxo de caixa.

- Fazer a gestão do valor contratado versus valor orçamentado da compra (controle de budget).

- Identificar os pontos de desvio de processo e propor uma solução para os problemas identificados, visando sempre a uma melhoria contínua dos processos da empresa.

Após implantação das ações e das melhorias no processo de compras, a empresa mensura os ganhos por meio dos relatórios extraídos do sistema, ao longo de cada etapa do processo, de modo a garantir a 
conformidade do processo com as políticas e dos procedimentos da empresa, segundo a seção 404 da Lei SOX.

Essas informações podem ser utilizadas para avaliar o desempenho e a eficiência da área de sourcing e demais envolvidas ao longo da cadeia no cumprimento das metas estabelecidas pela empresa.

Após a implantação completa do macroprocesso end-to-end demonstrado na Figura 1, espera-se obter processos operacionais mais eficientes.

\section{CONTRIBUIÇÃO TECNOLÓGICA/ SOCIAL}

A contribuição deste estudo está em analisar e discutir a relevância do uso de um sistema do tipo ERP para automação dos registros contábeis e financeiros, especialmente na integração dos processos e no estabelecimento de controles internos eficientes para a área de sourcing das despesas operacionais - SG\&A (Opex) - e de investimentos (Capex), por meio de um processo de compras integrado end-to-end.

Após a implantação desse macroprocesso integrado, a empresa passa a ter uma matriz de segregação intersistemas, em vez de intrassistemas (CALDEIRA, 2008), dando uma visão de governança aos gestores e proporcionando maior confiabilidade na avaliação sobre a eficácia dos controles internos e procedimentos estabelecidos na empresa, fundamental para geração dos relatórios em conformidade com a seção 404 da Lei SOX.

Assim, de modo a potenciar os benefícios de um processo integrado, cabe à empresa, adicionalmente, as seguintes ações:

- Garantir a transparência no processo de compras de bens ou a contratação de serviços.

- Realizar a gestão do processo de compra com as empresas contratadas, garantindo que todas as compras que não passam pelo processo licitatório (Bid) implicam uma classificação como um desvio de processo ou uma compra de emergência.

- Aprovar os documentos, de modo sistêmico, de acordo com as alçadas definidas em cada etapa do processo.

- Fazer a gestão do tempo médio de entrega de pedidos.

- Identificar os pedidos em aberto acima de $\mathrm{x}$ dias sem a entrega efetiva de material ou realização do serviço. 
- Controlar as quebras de pedidos para driblar as alçadas de aprovação (quantidade de pedido, mesmo fornecedor, mesmo item, mesma unidade no período de $\mathrm{x}$ dias).

- Identificar os pedidos emitidos após entrega do material ou realização do serviço (data do pedido após a emissão da nota fiscal).

- Fazer a gestão do prazo médio de pagamento (data de entrega do material versus data do pagamento).

- Realizar de forma eficiente a gestão do fluxo de caixa.

- Fazer a gestão do valor contratado versus valor orçamentado da compra (controle de budget).

- Identificar os pontos de desvio de processo e propor uma solução para os problemas identificados, visando sempre a uma melhoria contínua dos processos da empresa.

Do ponto de vista da análise teórica, a Lei SOX apresenta os requisitos necessários para um sistema de controle interno eficiente, aqui aplicados na área de compras, e a teoria institucional se mostra aplicável em todas as etapas do macroprocesso aqui apresentado. Sem dúvida, a necessidade de a empresa ter um sistema de con- trole interno implica um método que avalie a estrutura desse sistema e a sua adequação a ela.

Do ponto de vista da análise empírica, propõe-se um processo de compras baseado no macroprocesso end-to-end, garantindo que o sistema de controle interno é o apoio essencial às decisões de compras de materiais, bens e serviços, equilibrando as despesas gerais, operacionais e administrativas - SG\&A (Opex) - e os gastos de investimento (Capex). Assim, é utilizado o conceito de um sistema integrado do tipo ERP, como um pacote, conforme sugerido por Malmi e Brown (2008), cujas ferramentas de controle possam auxiliar os gestores no processo decisório e na execução de suas atividades em conformidade com a Lei SOX.

É importante a verificação das rotinas da área de sourcing, do mapeamento dos seus processos, do sistema de controle interno existente, e que podem ser melhorados, da análise dos pontos fortes e fracos, da verificação de não conformidades, falhas e os possíveis retornos positivos que esse processo pode trazer à empresa.

O modelo de macroprocesso de compras integrado apresentado pode ser adequado a uma empresa multinacional, ou a 
qualquer empresa, com as devidas adaptações, para que os benefícios demonstrados possam ser concretizados.

Entretanto, a empresa deve testar a viabilidade desse processo no curto prazo, com um tempo mínimo necessário para a sua implantação total, a depender do tamanho e da complexidade da empresa.

\section{SARBANES-OXLEY LAW:} RELEVANCE OF THE USE OF AN ERP TYPE SYSTEM FOR THE AUTOMATION OF ACCOUNTING AND FINANCIAL RECORDS

\section{ABSTRACT}

The development of information technology and information technologies have contributed to the processes of generation, diffusion, storage of knowledge in organizations are always in the process of change and to better meet the demands of organizations. The challenges related to the integration of technology and management processes and systems are to identify possible nonconformities, errors, duplications or failures that can guide managers to promote improvement opportunities and that can guarantee compliance with the policies and procedures established by the Company. The contribution of this study is to analyze and discuss the relevance of the use of an ERP system.
It is related to the automation of accounting and financial records, especially in the integration of processes and the establishment of efficient internal controls for the area of SG\&A (Opex) and Capex, through an end-to-end integrated purchasing process, to comply with the provisions of the Sarbanes-Oxley Act (SARBANES; OXLEY,2002).

\section{KEYWORDS}

Operating expenses. Sarbanes-Oxley Law. Integrated financial records. ERP.

\section{REFERÊNCIAS}

CALDEIRA, M. Sistema de informação para a gestão. Lisboa: Universidade Aberta, 2008 .

CAMPOS FILHO, M. P. de. Os sistemas de informação e as modernas tendências da tecnologia e dos negócios. Revistas de Administração de Empresas, São Paulo, v. 34, n. 6, p. 33-45, nov./dez. 1994. Disponível em: http://www.scielo.br/pdf/ rae/v34n6/a05v34n6. Acesso em: 15 fev. 2019.

CLEGG, S. R.; HARDY, C.; NORD, W. R. Handbook de estudos erganizacionais: modelos de análise e novas questões em estudos organizacionais. São Paulo: Atlas, 2012. 


\section{COMITÊ DE PRONUNCIAMENTOS CON-} TÁBEIS. Estrutura conceitual para elaboração e divulgação de relatório contábil financeiro CPC 00 (R1). São Paulo: CPC, 2011.

DELOITTE. Os poderosos do varejo global 2018: transformações significativas, comércio revigorado. Deloitte Touche Tohmatsu Limited. [S. 1.]. 2018.

DEVARAJ, S.; MISHRA, A. N.; VAIDYANATHAN, G. Effect of purchase volume flexibility and purchase mix flexibility on e-procurement performance: an analysis of two perspectives. Journal of Operations Management, v. 30, n. 7-8, p. 509-520, Nov. 2012. Disponível em: https://doi. org/10.1016/j.jom.2012.08.001. Acesso em: 23 mar. 2019.

DIAS, M. A. P. Administração de materiais, princípios, conceitos e gestão. 6. ed. São Paulo: Atlas, 2012.

ELIAS, T. M.; BORGERT, A.; LUNKES, R. J. Análise da composição dos custos e despesas em diferentes continentes. Contabilidad y Negocios, v. 13, n. 26, p. 1-18, 2018. Disponível em: http://revistas. pucp.edu.pe/index.php/contabilidadyNegocios/article/view/20531/20409. Acesso em: 25 mar. 2019.

FREZATTI, F. et al. Processo orçamentário: uma aplicação da análise substantiva com utilização da grounded theory. Organizações \& Sociedade, v. 18, n. 58, p. 445-466, 2011. Disponível em: http:// dx.doi.org/10.1590/S1984-92302011000300006. Acesso em: 20 mar. 2019.

HENDRIKSEN, E. S. Teoria da contabilidade. Tradução Antonio Zoratto Sanvicente. 5. ed. São Paulo: Atlas, 2018.

INSTITUTO DE ESTUDOS PARA O DESENVOLVIMENTO INDUSTRIAL. Análise IEDI Empresas. 2018. Disponível em: https://www.iedi.org.br/artigos/top/ analise/analise_iedi_20180912_empresas.html. Acesso em: 2 abr. 2019.

KETIKIDIS, P. H. et al. Applying: the EPOS eprocurement system in the healthcare paradigm. International Journal of Systems Science, v. 41, n. 3, p. 281-299, 2010. Disponível em: https://doi. org/10.1080/00207720903326878. Acesso em: 23 mar. 2019.

LOPES, A. B.; MARTINS, E. Teoria da contabilidade: uma nova abordagem. São Paulo: Atlas, 2007.

MALMI, T.; BROWN, D. A. Management control systems as a package: opportunities, challenges and research directions. Management Accounting Research, London, v. 19, n. 4, p. 287-300, Dec. 2008. Disponível em: https://doi.org/10.1016/j. 
mar.2008.09.003. Acesso em: 15 jan. 2019.

MOURA, B. C. Logística: conceitos e tendências. Lisboa: [s. n.], 2006.

PLOSSL, G. W. Administração da produção: como as empresas podem aperfeiçoar as operações a fim de competirem globalmente. São Paulo: Makron Books, 1993.

R\&D SOLUTIONS, A practical guide to achieving and maintaining global oversight and ensuring end-to-end pharmacovigilance. White Paper. Elsevier. [S. l.], p. 8-8. 2016.

SARBANES, P. S.; OXLEY, M. G. SarbanesOxley Law. American Institute of CPAs, 2002. Disponível em: https://www.aicpa. org. Acesso em: 15 jan. 2019.

SILVEIRA, A. M. Governança corporativa e estrutura de propriedade: determinantes e relação com o desempenho das empresas no Brasil. 2004. Tese (Doutorado em Controladoria e Contabilidade) - Universidade de São Paulo, São Paulo, 2004.

STEDE, W. A. V. D.; MARKYOUNG, S.; CHEN, C. X. Assessing the quality of evidence in empirical management accounting research: the case of survey studies. Accounting, Organizations and Society, v. 30, n. 7, p. 655-684, Oct./Nov. 2005. Disponível em: https://doi.org/ 10.1016/j.aos.2005.01.003. Acesso em: 23 mar. 2019. 